\title{
Simultaneous Quantification of Lupeol, Stigmasterol and $\beta$ - Sitosterol in Extracts of Adhatoda vasica Nees Leaves and its Marketed Formulations by a Validated RP-HPLC Method
}

\author{
Nandhini S', llango $K^{1,2, *}$
}

Nandhini $\mathbf{S}^{1}$, llango $\mathbf{K}^{1,2, *}$

'Division of Pharmacognosy and Phytochemistry, Interdisciplinary Institute of Indian System of Medicine (IIISM), SRM Institute of Science and Technology, Kattankulathur - 603203 , Chengalpattu (Dt), Tamil Nadu, INDIA.

2Department of Pharmaceutical Chemistry, SRM College of Pharmacy, SRM Institute of Science and Technology, Kattankulathur603 203, Chengalpattu (Dt), Tamil Nadu, INDIA.

\section{Correspondence}

Ilango Kaliappan

Division of Pharmacognosy and

Phytochemistry, Interdisciplinary Institute

of Indian System of Medicine (IIISM)

Department of Pharmaceutical Chemistry,

SRM College of Pharmacy SRM Institute

of Science and Technology, Kattankulathur

- 603 203, Chengalpattu (Dt), Tamil Nadu,

INDIA.

E-mail: ilangok67@gmail.com

History

- Submission Date: 01-04-2020;

- Review completed: 18-04-2020;

- Accepted Date: 04-05-2020;

DOI : 10.5530/pj.2020.12.122

Article Available online

http://www.phcogj.com/v12/i4

\section{Copyright}

( $) 2020$ Phcogj.Com. This is an openaccess article distributed under the term of the Creative Commons Attribution 4.0 International license.

\begin{abstract}
Background: Adhatoda vasica Nees (Acanthaceae) is a well-known medicinal plant used for the treatment of respiratory disorders such as asthma and bronchitis. Objective: To develop a simple and precise RP-HPLC method for the simultaneous assessment of lupeol, stigmasterol and $\beta$-sitosterol of various extracts of Adhatoda vasica Nees. Materials and Methods: The compounds were separated on RP-Phenomenex $C_{18}(250 \mathrm{~mm} \times 4.6 \mathrm{~mm} ; 5 \mu)$ column with a mobile phase comprising of $0.1 \% \mathrm{v} / \mathrm{v}$ formic acid in water and methanol $(28: 82 \% \mathrm{v} / \mathrm{v})$ splashed at a flow of $0.8 \mathrm{~mL} / \mathrm{min}$ with PDA detector at $208 \mathrm{~nm}$. Results: The retention time of lupeol, stigmasterol and $\beta$-sitosterol was found to be $16.89,18.26$ and 20.72 minutes respectively. The amount of lupeol was abundant in hexane extract $(0.952 \% \mathrm{w} / \mathrm{W})$ and formulation III $(23.72 \mathrm{ng} / \mathrm{g})$ whereas, stigmasterol $(0.285 \% \mathrm{w} / \mathrm{w})$ and $\beta$-sitosterol $(8.649 \% \mathrm{w} / \mathrm{w})$ was highly abundant in chloroform extract and formulation I stigmasterol $(2.57 \mathrm{ng} / \mathrm{g})$ and $\beta$-sitosterol $(0.98 \mathrm{ng} / \mathrm{g})$. The optimized method was validated for different parameters and all the validated constraints were within the limits as per $\mathrm{ICH}$ guidelines. The proposed method was linear over the concentration range of $12.5-200 \mu \mathrm{g} / \mathrm{mL}$ with correlation coefficients greater than 0.997 . The LOD and LOO values of lupeol, stigmasterol and $\beta$-sitosterol were found to be $0.66,5.64$ and $12.8 \mu \mathrm{g} / \mathrm{mL}$ and $2.01,17.10$ and $36.62 \mu \mathrm{g} / \mathrm{mL}$ respectively. Conclusion: To conclude, the developed method for the simultaneous estimation of lupeol, stigmasterol and $\beta$-sitosterol was simple, precise, accurate and thus reliable for the quality control investigations of crude drugs and its herbal formulations.
\end{abstract}

Key words: Adhatoda vasica Nees, HPLC, Lupeol, Simultaneous quantification, $\beta$-sitosterol, Stigmasterol.

\section{INTRODUCTION}

Standardization is a significant tool for ensuring the quality of herbal drugs. The drug identity, purity, content, chemical and other biological properties determine the quality of the products. Quantitative estimation of chemical markers within the crude drugs is usually troublesome. Separation of markers using optimal separation techniques offer high resolution of the compounds and least interferences. ${ }^{1}$ Herbal medicine has been utilized by $85 \%$ of the world's population since prehistoric eras for the treatment of a variety of diseases. ${ }^{2}$ Therapeutic efficacy and safety depend upon the quality of herbal medicine. Lack of quality control profiles created obstacles in the approval of ayurvedic medicines for healthcare needs. Establishment of quality control parameters gets affected due to the complexion nature in the chemical compounds and its variability of herbal medicines. Advancement in the modernized analytical methods is increased to subdue these complications by developing an effective separation of marker compounds. ${ }^{3}$ The approaches in chromatographic separation techniques made quantification of chemical markers in crude drugs with very limited clean-up. ${ }^{4}$ Mainly, reverse phaseliquid chromatography (RP-HPLC) used for the estimation of various chemical compounds existing in single drug or mixture of drugs and its herbal formulations.

Adhatoda vasica Nees (Acanthaceae), also known as Vasaka in Ayurveda, is a perennial shrub prevalent in the hot regions of Southeast Asia. ${ }^{6}$ The plant is extensively used in Indian system of medicine (ISM) for the medication of respiratory system related ailments such as cough, asthma, allergeninduced bronchial obstruction and it has been used as an herbal remedy for tuberculosis. ${ }^{7}$ The medicinal properties of $A$. vasica characteristic to the presence of active phytoconstituents such as alkaloids, glycosides, flavonoids, coumarins, quinines triterpenes, polysaccharides, polyphenols, vitamin C, proteins and essential oils etc. ${ }^{8} \mathrm{~A}$. vasica leaves contain tricyclic quinazoline alkaloids (pyrroquinazoline alkaloids) viz. a major alkaloid, vasicine, vasicinone and deoxyvasicine. ${ }^{7}$ Roots of $A$. vasica possess vasicol and vasicinolone, kaempferol and quercetin were present in the plant flowers. ${ }^{9}$ Apart from these, leaves and roots found to the presence of other metabolites including, terpenoids, steroids, saponins, proteins, amino acids, fats, gum resins and sugars. 
Formulation I and II are proprietary Ayurvedic medicine used for cough and jaundice, respectively. Formulation I contain A. vasica along with Curcuma longa, Taxus baccata, Asparagus racemosa, Piper longum, Withania somnifera, Emblica officinalis, Curcuma zedoaria and Tinospora cordifolia. Formulation II contains 15 more ingredients along with $A$. vasica. Formulation III is a versatile combination of medicinal plants having anti-inflammatory property to ease the respiratory tract infection. Apart from A. vasica, it contains Glycyrrhiza glabra, Curcuma longa, Piper longum and Solanum xanthocarpum.

Various chromatographic methods were reported for the estimation of alkaloids such as vasicine and vasicinone by HPTLC and HPLC in crude drug and its formulations. UHPLC/QqQLIT-MS/MS reported for the simultaneous determination alkaloids and flavonoids in $A$. vasica leaves. ${ }^{10}$ Several methods were available for the quantification of lupeol and stigmasterol, lupeol and $\beta$-sitosterol by both HPTLC and HPLC. ${ }^{11,12}$ and sterols by HPLC ${ }^{13,14}$ Literature survey revealed that there is no method available for the simultaneous estimation of lupeol, stigmasterol and $\beta$-sitosterol.

In the current investigation, we have established a simple, rapid and optimized HPLC method for the simultaneous estimation of lupeol, stigmasterol and $\beta$-sitosterol (Figure 1) in A. vasica extracts. A. vasica containing Ayurvedic formulations were also evaluated for lupeol, stigmasterol and $\beta$-sitosterol. The developed method was evaluated for different parameters and validated according to the International Conference on Harmonization (ICH) guidelines. ${ }^{15}$ Validation has been carried out based on its linearity, accuracy, precision, limit of detection and limit of quantification. This is the first report on simultaneous quantification of three markers in A. vasica leaf extracts.

\section{MATERIALS AND METHODS}

\section{Plant material}

A fresh matured leaf of $A$. vasica was collected from Allen Road, Tirumani, Chengalpattu district in the month of October 2017 with a latitude of 12.666 and longitude of 79.993. The taxonomic identification of the plants was confirmed by Prof. P. Jayaraman (Botanist), Plant Anatomy Research Centre, Tambaram, Chennai, Tamil Nadu, India. Voucher specimens (PARC/2018/3653) were deposited in the Herbarium of Interdisciplinary Institute of Indian System of Medicine (IIISM), SRM Institute of Science and Technology, Kattankulathur,
Kancheepuram, Tamil Nadu, India. The collected materials were cleaned, shade dried and pulverized in a blender, sieved through 60 mesh sieve and well-preserved in amber coloured airtight container at room temperature.

\section{Standards and reagents}

Lupeol (97\%), stigmasterol (99\%) and $\beta$-sitosterol (98\%) standards were procured from Natural Remedies Pvt. Ltd, Bangalore, India. Formulation I, II and III were purchased from Ayurvedic pharmacy, Metabolic ward, Interdisciplinary Institute of Indian System of Medicine (IIISM), SRM Institute of Science and Technology, Kattankulathur. Formic acid (analytical grade), methanol (HPLC grade) were procured from Ranchem Private Limited. Mill-Q-water from Millipore was used. Chemicals of analytical grade were obtained from Merck Specialities Private Limited, Mumbai.

\section{Extraction of $A$. vasica}

Each $150 \mathrm{~g}$ of powdered A. vasica were extracted in $750 \mathrm{ml}$ of hexane, chloroform, ethyl acetate and methanol for $72 \mathrm{~h}$ at room temperature for non-successive extraction. The extracts were filtered and re-extracted thrice by following the same procedure. The filtrates were combined and concentrated under reduced pressure using a Buchi rotary evaporator.

\section{Preparation of Ayurvedic formulations}

Each 5 tablets of Formulation I and II were grinded in a mortar and pestle and $5 \mathrm{ml}$ of Formulation III were evaporated to dryness. $100 \mathrm{mg}$ of each sample were dissolved in $1 \mathrm{~mL}$ of methanol and sonicate for $15 \mathrm{~min}$. The sample was then filtered and made up to $1 \mathrm{~mL}$ of methanol.

\section{Instrumentation and chromatographic conditions}

Shimadzu LC-20AD HPLC system equipped with CT0-20A controller and the column oven. A Rheodyne 7725 injection valve with $20 \mu \mathrm{L}$ loop volume, an SPD-M20A photo-diode array detector and a Lab solution version 7.1 software was used for data acquisition and interpretation. Chromatographic separation was achieved on RP $\mathrm{C}_{18}$ Phenomenex column $(250 \mathrm{~mm} \times 4.6 \mathrm{~mm}$; i.d., $5 \mu \mathrm{m}$ pore size). The solvent mixture of $0.1 \%$ formic acid in water: methanol $(28: 82 \% \mathrm{v} / \mathrm{v})$ at a flow rate $0.8 \mathrm{~mL} /$ min, the column was maintained at room temperature and the PDA detector was fixed at $208 \mathrm{~nm}$.

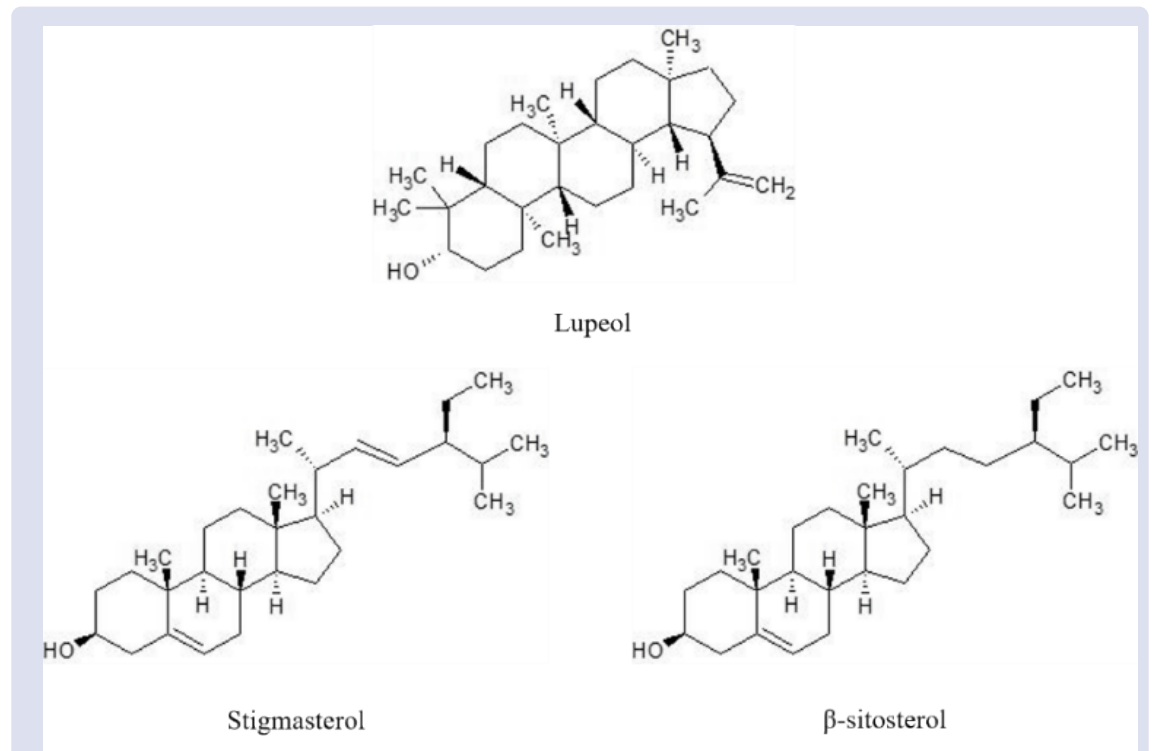

Figure 1: Chemical structure of lupeol, stigmasterol and $\beta$-sitosterol. 
Nandhini, et al.: Simultaneous Quantification of Lupeol, Stigmasterol and $\beta$ - Sitosterol in Extracts of Adhatoda vasica Nees Leaves and its Marketed Formulations by a Validated RP-HPLC Method

\section{Preparation of standards and samples}

Standard solutions of lupeol, stigmasterol and $\beta$-sitosterol were prepared and diluted in the concentration range of 12.5 to $200 \mu \mathrm{g} / \mathrm{mL}$ in methanol for construction of calibration curve.

Methanolic stock solutions $(10 \mathrm{mg} / \mathrm{mL})$ of hexane, chloroform, ethyl acetate and methanolic extracts of $A$. vasica were prepared and filtered through a $0.22 \mu \mathrm{m}$ PVDF membrane and stored at $-20^{\circ} \mathrm{C}$.

\section{Development of calibration curve}

Calibration was achieved with six dilutions of standards, at concentrations ranging from 12.5 to $200 \mu \mathrm{g} / \mathrm{mL}$ and triplicate measurement was performed. The linearity of each standard attained by plotting peak areas versus standard concentrations. Identification of peak was attained by comparing both retention time $\left(R_{t}\right)$ and $U V$ absorbance $\left(\lambda_{\max }\right)$.

\section{Method validation}

According to the $\mathrm{ICH}$ guidelines, ${ }^{15}$ validation was performed for the developed method for linearity, accuracy, precision, LOD and LOQ. Linearity was performed in the concentration range of $12.5-200 \mu \mathrm{g} /$ $\mathrm{mL}$ of standards. The accuracy was calculated by means of percentage recovery, which was determined by the standard addition method. Standard solutions of $80 \%, 100 \%$ and $120 \%$ were spiked into the samples prior to the extraction and analysed under the optimized method to estimate the spiked recoveries. Precision was determined using repeatability and intermediate precision. Repeatability or intraday precision was determined by injecting the standards six times on the same day. Intermediate precision was performed with the same sample in the same way on different day. Limit of Detection (LOD) and Limit of Quantification (LOQ) of standards were estimated separately with a standard calibration curve.

\section{Statistical analysis}

The data were statistically analysed using the one-way analysis of variance (ANOVA). The results were presented as mean of three replicates \pm standard error of mean $($ SEM) $n=3$

\section{RESULTS AND DISCUSSION}

\section{Optimization of HPLC chromatographic conditions}

HPLC chromatographic conditions were optimized after running with a $\mathrm{C}_{18}$ reverse phase column using different mobile phases. All the three marker compounds showed a satisfactory response of detection wavelength at $208 \mathrm{~nm}$. Ambient temperature was maintained in the column till the completion of the analysis. A mobile phase of $28 \% \mathrm{v} / \mathrm{v}$ of $0.1 \%$ formic acid in water (A) and $82 \% \mathrm{v} / \mathrm{v}$ of methanol (B) used with $0.8 \mathrm{~mL} / \mathrm{min}$ flow rate in an isocratic elution. An HPLC fingerprint was developed for A. vasica extract with an optimized chromatographic condition.

\section{Quantification of marker compounds in A. vasica extracts}

The chemical markers were identified and quantified in A. vasica extracts and its formulation with respect to lupeol, stigmasterol and $\beta$-sitosterol. The chromatograms of lupeol, stigmasterol and $\beta$-sitosterol exhibited efficient separation of the three compounds. Hexane extract contained lupeol $(0.952 \% \mathrm{w} / \mathrm{w})$, stigmasterol $(0.255 \% \mathrm{w} / \mathrm{w})$ and $\beta$-sitosterol $(3.126 \% \mathrm{w} / \mathrm{w})$, chloroform extract contained lupeol $(0.548 \% \mathrm{w} / \mathrm{w})$, stigmasterol $(0.285 \% \mathrm{w} / \mathrm{w})$ and $\beta$-sitosterol $(8.649 \% \mathrm{w} / \mathrm{w})$, ethyl acetate extract contained lupeol $(0.487 \% \mathrm{w} / \mathrm{w})$, stigmasterol $(0.105 \% \mathrm{w} / \mathrm{w})$ and $\beta$-sitosterol $(1.472 \% \mathrm{w} / \mathrm{w})$ while methanolic extract contained lupeol $(0.105 \% \mathrm{w} / \mathrm{w})$, stigmasterol $(0.113 \% \mathrm{w} / \mathrm{w})$ and $\beta$-sitosterol $(5.062 \% \mathrm{w} / \mathrm{w})$. Each sample was performed in triplicate and the standard and sample chromatograms were shown in Figure 2 and summarized in Table 1.

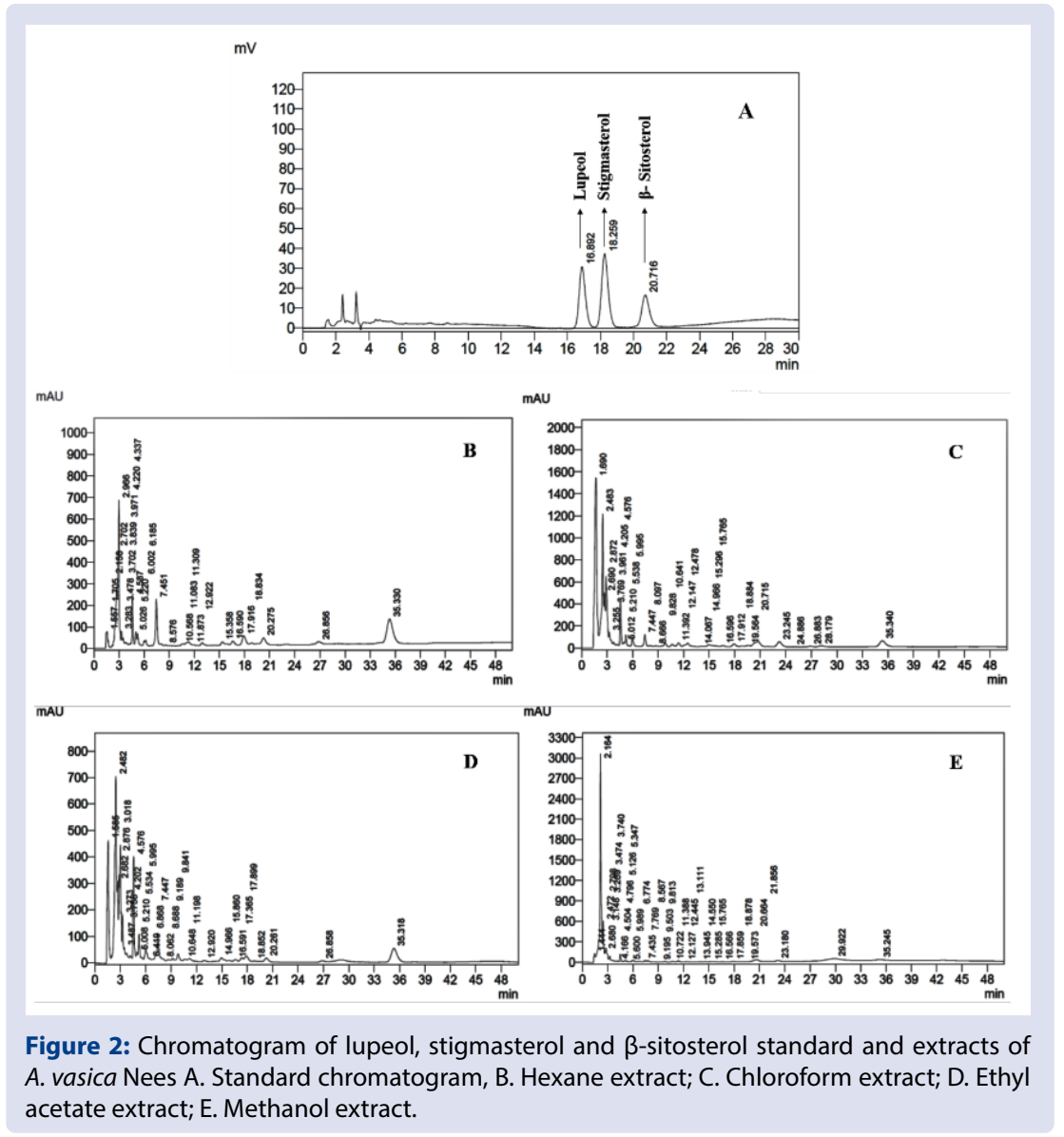




\section{Quantification of marker compounds in marketed formulation}

The marker compounds were identified and quantified in the ayurvedic formulations depicted in Figure 3 and Table 2. Formulation III revealed the presence of high content of lupeol (23.72ng/g) whereas stigmasterol $(2.57 \mathrm{ng} / \mathrm{g})$ and $\beta$-sitosterol $(0.98 \mathrm{ng} / \mathrm{g})$ content were more in Formulation I.

\section{Method validation for HPLC fingerprinting analysis}

The developed RP-HPLC methodology was validated and evaluated by determining the range and linearity, accuracy, precision, LOD and LOQ. The technique was also assessed for qualitative analysis by considering the precision and selectivity of eluted chemical marker. Repeatability was achieved with a high concentration of standards and extracts. Linearity, precision, accuracy, LOD and LOQ were estimated for the quantification of markers. The determination of LOD and LOQ were 0.66 and $2.01 \mu \mathrm{g} / \mathrm{mL}$ for lupeol, 5.64 and $17.10 \mu \mathrm{g} / \mathrm{mL}$ for stigmasterol and 12.08 and $36.62 \mu \mathrm{g} / \mathrm{mL}$ for $\beta$-sitosterol, correspondingly. The linearity of three markers was obtained with concentrations versus peak areas in the concentration range of $12.5-200 \mu \mathrm{g} / \mathrm{mL}$ and $\mathrm{R}^{2}$ were higher than 0.99 (Table 3). $98.19-102.31 \%$ of recovery of the compounds showed an acceptable accuracy. Relative standard deviation (RSD) of all compounds was less than $2 \%$, a representative for high repeatability (Table 4). Precision and intermediate precision have a very low coefficient of variation reveals the method is precise (Table 5). The method validation parameters were shown in Figure 4.

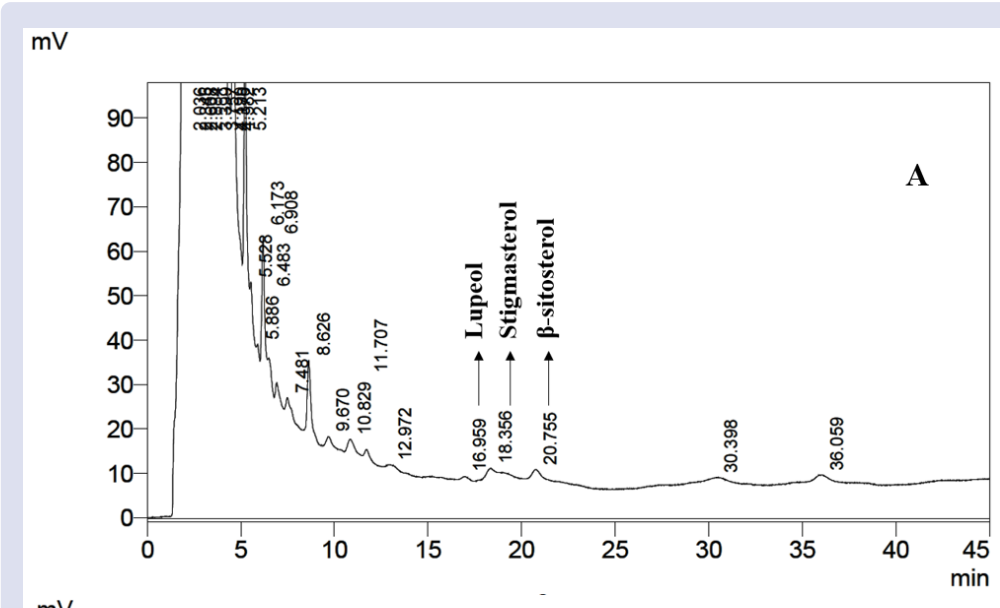

$\mathrm{mV}$

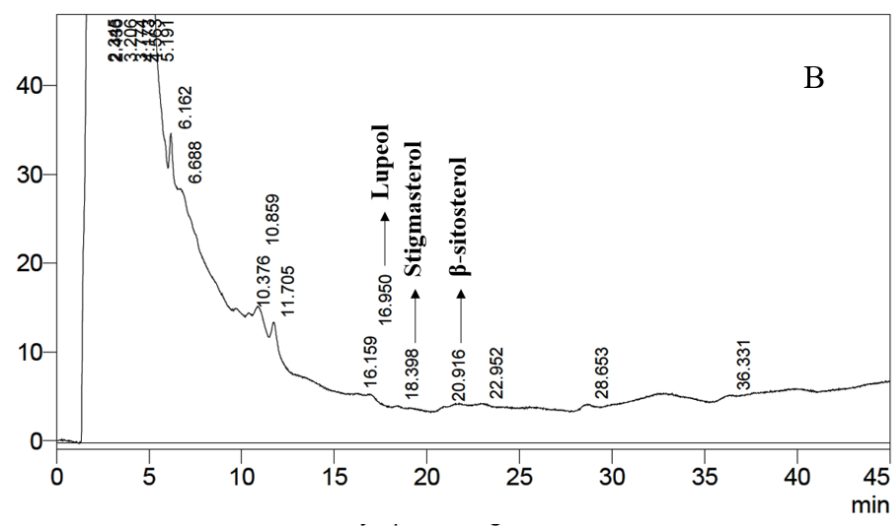

$\mathrm{mV}$

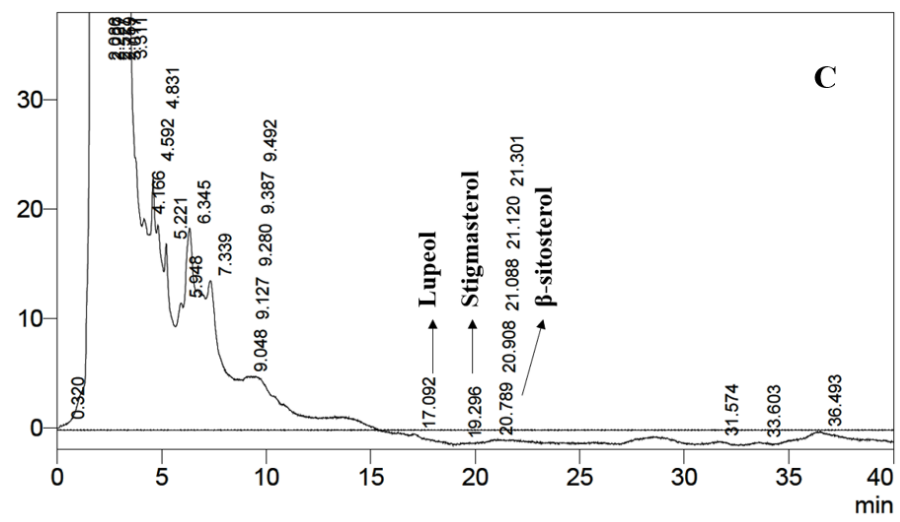

Figure 3: Chromatogram of A. vasica containing Ayurvedic formulations A). Formulation I, B). Formulation II and C) Formulation III. 
Nandhini, et al.: Simultaneous Quantification of Lupeol, Stigmasterol and $\beta$ - Sitosterol in Extracts of Adhatoda vasica Nees Leaves and its Marketed Formulations by a Validated RP-HPLC Method

Table 1: Quantification of lupeol, stigmasterol and $\beta$-sitosterol in $A$. vasica by RP-HPLC method.

\begin{tabular}{cccc}
\hline Extracts & Lupeol $(\% \mathrm{w} / \mathrm{w})$ & Stigmasterol $(\% \mathrm{w} / \mathrm{w})$ & $\beta$-sitosterol $(\% \mathrm{w} / \mathrm{w})$ \\
\hline Hexane & $0.952 \pm 0.02$ & $0.255 \pm 0.02$ & $3.126 \pm 0.02$ \\
Chloroform & $0.548 \pm 0.01$ & $0.285 \pm 0.01$ & $8.649 \pm 0.04$ \\
Ethyl acetate & $0.487 \pm 0.02$ & $0.105 \pm 0.03$ & $1.472 \pm 0.01$ \\
Methanol & $0.105 \pm 0.05$ & $0.113 \pm 0.01$ & $5.062 \pm 0.02$ \\
\hline
\end{tabular}

Data are represented as mean $\pm S D(n=3)$

Table 2: Quantification of lupeol, stigmasterol and $\beta$-sitosterol in $A$. vasica containing formulations by RPHPLC method.

\begin{tabular}{cccc}
\hline Formulations & Lupeol $(\mathrm{ng} / \mathrm{g})$ & Stigmasterol $(\mathrm{ng} / \mathrm{g})$ & $\beta$-sitosterol $(\mathrm{ng} / \mathrm{g})$ \\
\hline Formulation I & $4.20 \pm 0.03$ & $2.57 \pm 0.01$ & $0.98 \pm 0.05$ \\
Formulation II & $8.09 \pm 0.04$ & $0.36 \pm 0.02$ & $0.27 \pm 0.06$ \\
Formulation III & $23.72 \pm 0.02$ & $1.10 \pm 0.02$ & $0.63 \pm 0.03$ \\
\hline
\end{tabular}

Data are represented as mean $\pm S D(n=3)$

Table 3: Regression parameter, linearity, limit of detection (LOD) and limit of quantification (LOQ) of the proposed RP-HPLC method.

\begin{tabular}{ccccccc}
\hline Compounds & $\begin{array}{c}\text { Concentration } \\
\text { range }(\mu \mathrm{g} / \mathrm{mL})\end{array}$ & $\mathrm{R}_{\mathrm{t}}(\mathrm{min})$ & $\begin{array}{c}\text { Regression } \\
\text { equation }\end{array}$ & $\mathrm{R}^{2}$ & $\mathrm{LOD}(\mu \mathrm{g} / \mathrm{mL})$ \\
\hline Lupeol & $12.5-200$ & $16.811 \pm 0.08$ & $\mathrm{y}=4197.1 \mathrm{x}-841.56$ & 0.9997 & 0.66 \\
Stigmasterol & $12.5-200$ & $18.150 \pm 0.11$ & $\mathrm{y}=5387.9 \mathrm{x}-9212.1$ & 0.9994 & 5.64 \\
$\boldsymbol{\beta}$-sitosterol & $12.5-200$ & $20.588 \pm 0.12$ & $\mathrm{y}=2667.4 \mathrm{x}-9767.9$ & 0.9976 & 17.10 \\
\hline
\end{tabular}

Data are represented as mean $\pm S D(n=6)$

Table 4: Recovery study of three markers present in A. vasica.

\begin{tabular}{|c|c|c|c|c|}
\hline Compounds & Amount added $(\mathrm{mg} / \mathrm{g})$ & Recorded amount (mg) & Recovery rate (\%) & $\%$ RSD \\
\hline \multirow{3}{*}{ Lupeol } & 80 & $1.001 \pm 0.03$ & $100.13 \pm 3.48$ & 1.48 \\
\hline & 100 & $0.996 \pm 0.02$ & $99.64 \pm 1.77$ & 1.77 \\
\hline & 120 & $1.014 \pm 0.03$ & $101.44 \pm 3.05$ & 1.95 \\
\hline \multirow{3}{*}{ Stigmasterol } & 80 & $1.012 \pm 0.04$ & $101.18 \pm 4.23$ & 1.23 \\
\hline & 100 & $0.982 \pm 0.02$ & $98.22 \pm 2.39$ & 1.39 \\
\hline & 120 & $1.023 \pm 0.02$ & $102.31 \pm 2.26$ & 1.76 \\
\hline \multirow{3}{*}{$\beta$-sitosterol } & 80 & $0.982 \pm 0.05$ & $98.19 \pm 5.14$ & 1.94 \\
\hline & 100 & $1.004 \pm 0.03$ & $100.42 \pm 2.96$ & 1.96 \\
\hline & 120 & $1.005 \pm 0.05$ & $100.51 \pm 5.25$ & 1.25 \\
\hline
\end{tabular}

Data are represented as mean $\pm S D(n=3)$

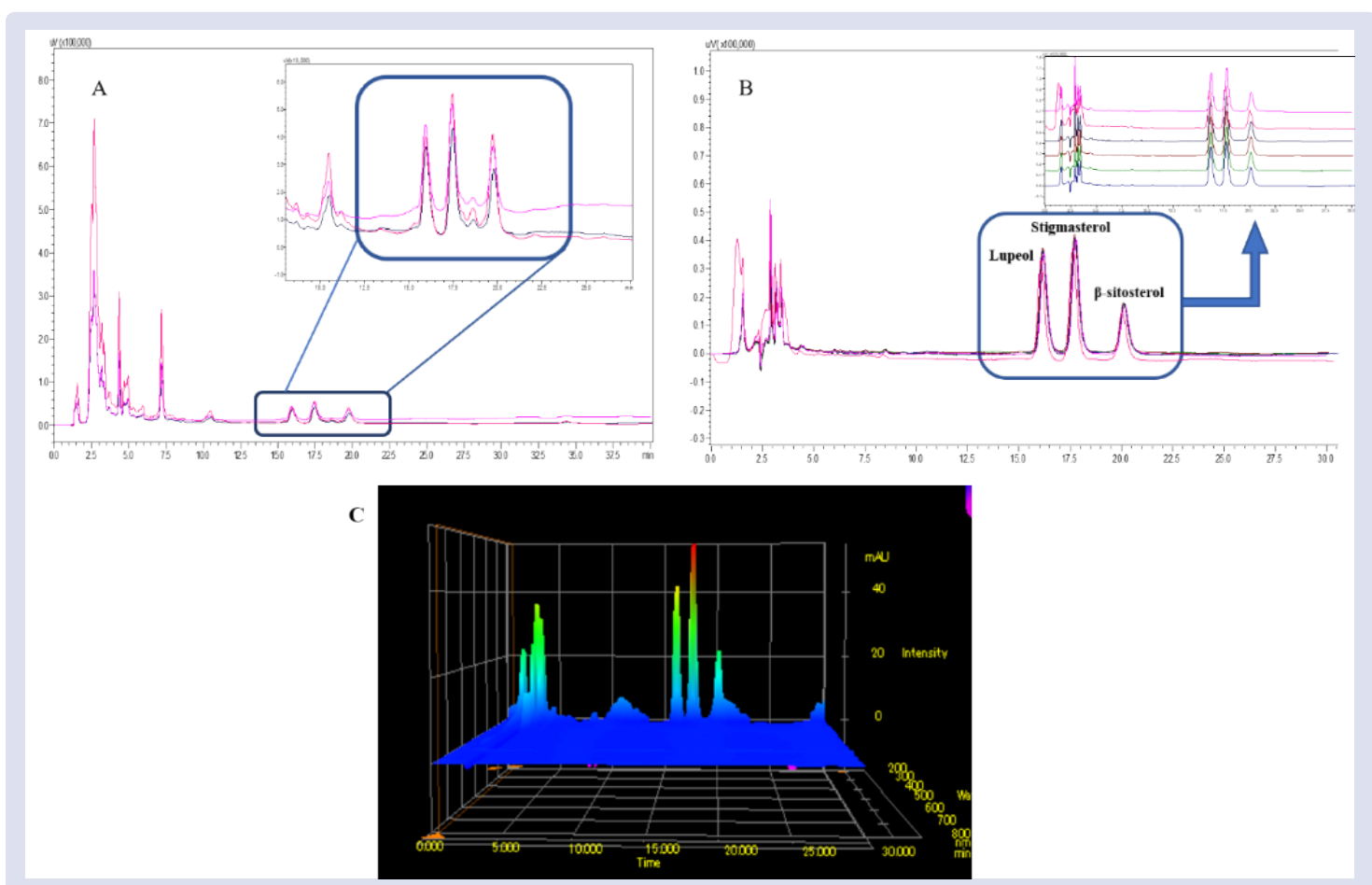

Figure 4: Validation parameters of lupeol, stigmasterol and $\beta$-sitosterol A. Accuracy B. Precision C. Overlay of system precision chromatogram. 
Nandhini, et al.: Simultaneous Quantification of Lupeol, Stigmasterol and $\beta$ - Sitosterol in Extracts of Adhatoda vasica Nees Leaves and its Marketed Formulations by a Validated RP-HPLC Method

Table 5: Precision of the intra-day and inter-day HPLC measurement for lupeol, stigmasterol and $\beta$-sitosterol in $A$. vasica.

\begin{tabular}{cccc}
\hline \multirow{2}{*}{ Compounds } & \multicolumn{2}{c}{ Intra-day } & \multicolumn{2}{c}{ Inter-day } \\
\cline { 2 - 4 } & Contents (\%w/w) & RSD (\%) & Contents (\%w/w) \\
\hline Lupeol & $1.195 \pm 0.01$ & 1.22 & $1.149 \pm 0.01$ \\
Stigmasterol & $4.159 \pm 0.07$ & 1.64 & $4.210 \pm 0.06$ \\
$\beta$-sitosterol & $0.326 \pm 0.01$ & 1.71 & $0.317 \pm 0.01$ \\
\hline
\end{tabular}

Data are represented as mean $\pm S D(n=6)$

\section{CONCLUSION}

Standardization of ayurvedic plants possesses problem in the identification and quantification of chemical markers. The proper identification and estimation require optimized method development and validation. The crude drugs and polyherbal formulation need special attention for the method development since incompatible sample preparation can cause significance in the recovery of the compounds. Taking all factors into consideration, we have reported a unique RPHPLC method for the identification and simultaneous quantification of lupeol, stigmasterol and $\beta$-sitosterol in A. vasica extracts and its Ayurvedic formulations. The developed method provides optimum separation in such a way that gives maximum resolution and avoids merging of compounds. Further, the developed method was validated for different parameters and found accurate, reproducible, specific and precise. The proposed method is suitable for the routine analysis of lupeol, stigmasterol and $\beta$-sitosterol in different crude plants as well as polyherbal formulations.

\section{CONFLICTS OF INTEREST}

None.

\section{ABBREVIATIONS}

ISM- Indian System of Medicine; RP-HPLC-PDA- Reverse phase high performance liquid chromatography-photodiode array; A. vasicaAdhatoda vasica; PARC- Plant anatomy research centre; PVDFPolyvinylidene fluoride; LOD- Limit of Detection; LOQ-Limit of Quantification; UV-Ultraviolet; RSD- Relative standard deviation; ANOVA- Analysis of Variance; SEM- Standard error of mean.

\section{REFERENCES}

1. Ong ES. Extraction methods and chemical standardization of botanicals and herbal preparations. J Chromatogr B. 2004;812(1-2):23-33.

2. WHO: WHO Traditional Medicine Strategy 2013. 26.

3. Asolkar L, Kakkar K, Chakre O. Glossary of indian medicinal plants with active principles; CSIR: New Delhi, 1992;187.
4. Dhalwal K, Biradar YS, Rajani M. High-performance thin-layer chromatography densitometric method for simultaneous quantitation of phyllanthin hypophyllanthin, gallic acid, and ellagic acid in Phyllanthus amarus. J AOAC Int 2006;89(3):619-23

5. Sheu S J, Li KL. Liquid Chromatographic determination of the constituents in Shao-Yao-Tang and related chinese herbal preparations. HRC J High Resolut Chromatogr. 1998;21(10):569-73.

6. Hossain MT, Hoq MO. Therapeutic use of Adhatoda vasica. Asian J Med Biol Res. 2016;2(2):156-63.

7. Sampath KKP, BhowmikD, Tiwari P, Kharel R. Indian traditional herbs Adhatoda vasica and its medicinal application. J Chem Pharm Res. 2010;2(21):240-45.

8. Karthikeyan A, Shanthi $V$, Nagasathaya A. Preliminary phytochemical and antibacterial screening of crude extract of the leaf of Adhatoda vasica $L$. Int $J$ Green Pharm. 2009;3(1):78-80.

9. Srinivasan M, Padmaja B, Nair S. GC-MS profiling and in vitro radical scavenging effect of Adhatoda beddomei. J Pharmacogn Phytochem. 2014;2(5):55-9.

10. Singh A, Kumar S, Bajpai V, Kumar B. Simultaneous determination of pyrroquinazoline alkaloids and flavonoids in Adhatoda beddomei and Adhatoda vasica and their marketed herbal formulations using ultra-high-performance liquid chromatography coupled with triple quadrupole linear ion trap mass spectrometer. Biomed Chromatogr. 2017;31(3):3827.

11. Hussain M, Sheeba F, Mohammad A, AlamM, Rahman M, Srivastava A Phytochemical investigation and simultaneous estimation of bioactive lupeol and stigmasterol in Abutilon indicum by validated HPTLC method. J Coast Life Med. 2014;2(5):394-401.

12. Shilajan S, Swar G. Simultaneous estimation of three triterpenoids-ursolic acid $\beta$-sitosterol and lupeol from flowers, leaves and formulations of Rhododendron arboreum Smith. using validated HPTLC method. Int J Green Pharm. 2013;7(3):206-10

13. Jadhav R, Shah U, Patel P, Patel S, Hingorani L. Development and validation of a simple isocratic HPLC method for simultaneous estimation of phytosterols in Cissus quadrangularis. Indian J Pharm Sci. 2011;72(6):753.

14. Vemuri S, Ramasamy MK, Rajakanu P, Kumar RCS, Kalliappan I. Application of chemometrics for the simultaneous estimation of stigmasterol and $\beta$-sitostero in Manasamitra Vatakam-an ayurvedic herbomineral formulation using HPLCPDA method. J Appl Pharm Sci. 2018;8(7):1-9.

15. International Conference on Harmonization of technical requirements for registration of pharmaceutical for human use. $\mathrm{ICH}$ harmonised tripartite guideline. (2005) Validation of analytical procedures: text and methodology Q2(R1), 4th version; Geneva, Switzerland. 


\section{GRAPHICAL ABSTRACT}

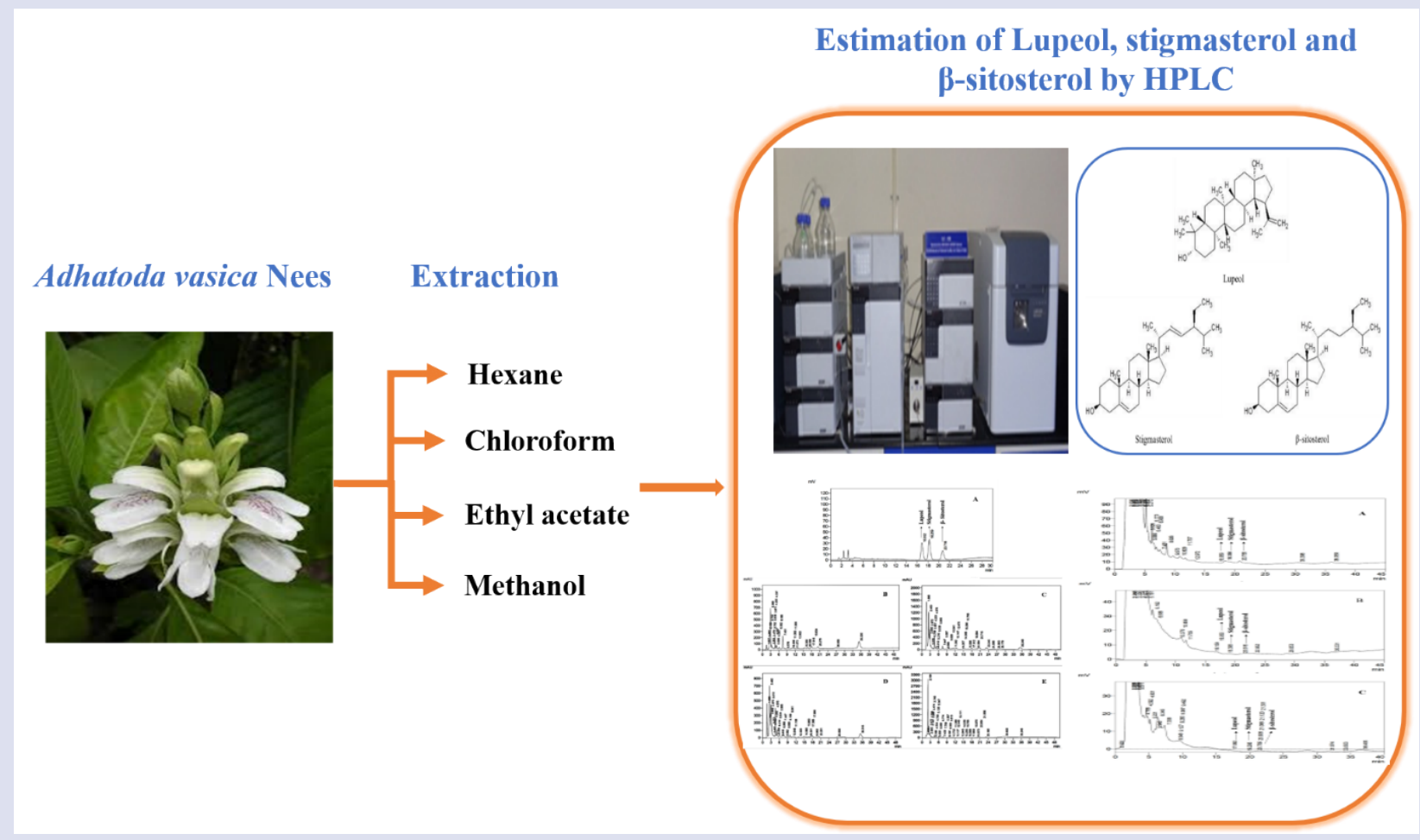

\section{ABOUT AUTHORS}

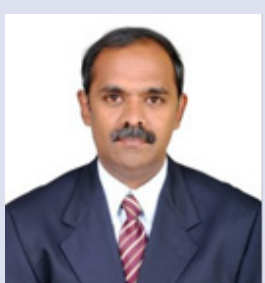

Dr.K.Ilango received his Ph.D from Sri Ramachandra Institute Higher education and Research, Chennai and his Master's degree from Birla Institute of Technology and Science, Pilani, Rajasthan and graduated from Annamalai University, Chidambaram. His academic journey in SRM began in 1994. Since then, Dr. K. Ilango's involvement in Academics and Research had been remarkable. Currently he is working as Professor, SRM College of Pharmacy \& Dean, Interdisciplinary Institute of Indian System of Medicine, SRM Institute of Science and Technology, his contribution and sharing of knowledge has benefited several aspiring students.

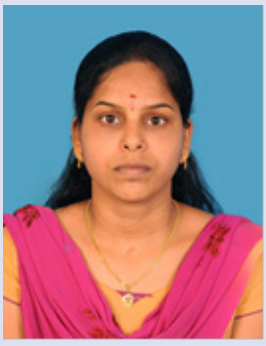

Ms.S.Nandhini has completed her Bachelors of Pharmacy and Masters of Pharmacy (Pharmacognosy) form Madras Medical College, Chennai. She is currently pursuing PhD under the supervision of Dr.K.Ilango at IIISM, SRM Institute of Science and Technology.

Cite this article: Nandhini S, llango K. Simultaneous Quantification of Lupeol, Stigmasterol and $\beta$ - Sitosterol in Extracts of Adhatoda vasica Nees Leaves and its Marketed Formulations by a Validated RP-HPLC Method. Pharmacogn J. 2020;12(4):850-6. 